Clapham, D. (2017) Housing theory, housing research and housing policy. Housing, Theory and Society, 35(2), pp. 163-177. (doi: 10.1080/14036096.2017.1366937)

There may be differences between this version and the published version. You are advised to consult the publisher's version if you wish to cite from it.

http://eprints.gla.ac.uk/221903/

Deposited on 7 August 2020

Enlighten - Research publications by members of the University of Glasgow http://eprints.gla.ac.uk 


\title{
Housing theory, housing research and housing policy
}

\author{
David Clapham, University of Reading
}

\begin{abstract}
Jim Kemeny in 1992 criticised existing housing research for neglecting social theory and being overly positivist and policy focused. The result has been a strengthening of the conceptual basis of housing research in general, but also a growing schism between researchers who focus on policy relevancy and those that pursue more theoretical work. This paper challenges this schism and argues for theoretically based and policy relevant research. First the paper argues that the policy-making process is complex and can vary between different countries, situations and over time. Therefore, it is argued that many styles of research can influence policy in the right circumstances. Second, the paper challenges the idea that there can be theoretically-free housing research arguing that all research has a theoretical foundation even though in many studies it is not explicit. Finally, the paper engages with the debate about where theory for housing research should come from and what it would look like.
\end{abstract}

\section{Introduction}

In a seminal contribution to housing research Jim Kemeny (1992) lamented the state of research in the field. He argued that most housing research was explicitly a-theoretical, overly empirical and adopted the definition of the problem defined by governments and elites. He questioned the lack of concepts and theories drawn from the social sciences and advocated the application of the mainstream social science traditions. Kemeny's critique was influential and many academics followed his lead. The result has been much more theoretically informed housing research, but also a perceived schism between the followers of Kemeny, who have developed theoretical concepts in housing, and those who see the role of housing research as being to inform government housing policy, who have largely continued a tradition of empirical and implicitly positivist research. The focus of this paper is not to challenge Kemeny's call for more theoretical research, but to argue that theoretically oriented research can be policy relevant, which implies that the perceived schism is a misleading and inaccurate view of the state of housing research.

Therefore, the objective of this paper is to challenge the schism in housing research and to argue the case for theoretically informed research on housing that influences government housing policy. The argument begins with a brief review of theories of policy making. It is argued that the tradition of empirical policy related research is based on a particular view of the policy making process based on rationality, whereas there are many other perspectives on this process that offer better descriptions of policy making in practice. The different theoretical approaches to housing research are then reviewed and their fit for different forms of the policy making process assessed. 
Some reasons for the dominance of positivist and empirical research in the policymaking process are highlighted.

The paper then addresses the perceived lack of theoretical engagement in housing research. It argues that all research can be considered to be theoretical with the major factors being whether the theoretical framework is sufficiently explicit and the extent to which research makes new theory rather than applying existing theory.

Finally, the paper engages with the debate about the appropriate source of theory for housing research and argues for a distinctive set of housing theories. The conclusion is that housing research informed by housing theory has a great deal to offer housing policy.

\section{Making Housing Policy}

\section{What is housing policy?}

Before proceeding further, it is important to define what is meant by housing policy. In this paper housing policy is taken to mean 'any action taken by any government or government agency to influence the processes or outcomes of housing.' A number of items in this definition need to be explained in more detail.

There are many influences on housing policy. The term 'governance', used in contrast to the term 'government', shows acceptance here that policy is made through networks consisting of a number of public, private, voluntary and hybrid organisations. Therefore, it can be argued that policy is made by all of these organisations and so research aimed at policy relevance can be directed at any of these organisations. This is accepted, but at the same time the assumption is made here that the state holds a special place in this network and in many countries it is expected that the state takes ultimate responsibility for the outcomes of the housing system. Nevertheless, the argument of the paper holds even if it is thought that government agencies do not have this special position and policy relevance can be assessed in relation to a wide range of different agencies. Therefore, policy relevant research is defined as research that impacts on the policy process in some way, either directly or indirectly, and is used by any agency involved in that process.

Policy interventions may differ in their form and their scale. In terms of geographical scale, housing is global, national and local in its reach, although housing policy is usually essentially a national concern. However, in countries with a federal structure such as the US or Australia, the states will have a major role in policy alongside the national government, and in a devolved administration such as the UK, housing is one of the functions devolved to the constituent countries of Wales, Scotland and Northern Ireland. However, here policies that have a major impact on housing such as income support or economic policies are not devolved and so national parliaments or assemblies can find themselves without major policy tools and can have their efforts undermined by national government policies in retained fields.

Therefore, relevant government agencies can exist at many different levels. Some have responsibilities at the national level whereas others may be local municipal agencies 
that have local accountabilities and duties, although this may be within a national framework or financing structure. It is very common for housing to be both a national and a local responsibility with national governments setting the legal, financial and policy framework and local municipal authorities planning provision at the local level. Other agencies may be national in scope but accountable at arms-length to central government. An example may be a national housing bank that operates under a statutory framework, with its strategy and finance emanating from central government.

Whatever the scale of intervention, governments and government agencies have a number of types of mechanism that they can use. The first is regulation. This could involve setting the limits of action of private actors and institutionalizing social practices in the housing market. A common example would be regulation of the private rented sector that could involve controlling rents, constraining the activities of lettings agents and providing security of tenure to tenants. But regulation can also involve the regulation of behavior. For example, there has been a recent debate about the rise of conditionality in welfare state institutions where the aim of government is to use provision as a way of altering the behaviour of recipients. Examples may be taking on the responsibility of ownership by moving out of social housing or taking up employment or increasing hours of work, or moving to smaller accommodation. This regulation of behavior is stressed by writers in the tradition of Foucault (1979) and is often referred to by them as 'governmentality'.

The second form of intervention is direct provision. This may mean the national or local government or state agency directly building housing for sale or, more usually, for rent. Government may not undertake all of the stages of housing development in that it may contract out actual building work to private contractors or work with private housing developers. The example of direct provision most often encountered is the provision of social housing, but the state may provide other housing services, such as accommodation and support for homeless people.

The third form of intervention is through the provision of finance or subsidy. Government may make available grants or loans to individuals or organisations to achieve particular objectives. Payments to individuals may be to allow them to afford housing they otherwise would not be able to or to alter their perceptions, attitudes and behavior towards, for example, reducing energy use in a home or repairing the home. Grants to organisations such as private builders and developers may be designed to increase the supply of housing or to change its nature, by for example improving standards of energy efficiency.

The fourth form of intervention is through the provision of information or guidance. There are information asymmetries between participants in the buying and selling of houses. Therefore, government may act to provide some of this information or encourage or compel another party to provide it. Information and guidance may also be provided to vulnerable individuals who may have problems that mean that they may require help from social work or other professionals to be able to participate successfully in the housing process.

The fifth form of intervention is setting the patterns of accountability for organisations in housing. In other words government can define the relationships between the 
parties involved in housing. An example may be setting targets or monitoring procedures to ensure that social housing agencies have to consult their tenants in particular circumstances.

Sixth, governments are often active in the field of discourse around housing. In other words, they are important in setting the terms of discussion and debate and defining issues and problems. For example, countries differ in their attitude towards homelessness with some seeing it as a result of imperfections in the housing market and others as a personal failing by the homeless people themselves. Whichever discourse is dominant and accepted by government frames debate on the issue and defines the way the problem is defined and the actions taken to deal with it. Some policies will have a strong symbolic element in relation to political beliefs and ideologies. For example, owner occupation is sometimes thought to symbolize the importance of private property rights and to lend legitimacy to market relations and minimal state intervention.

The seventh form of intervention is non-intervention. Following the debate about the importance of non-decision making as a form of power emphasized by Lukes (1974), it is argued by Doling (1997) that choosing not to intervene in the market in general or in specific circumstances is a housing policy in its own right that will have specifiable outcomes.

The key point here is that policy involves several different forms of intervention that produce outcomes that involve the physical (in terms of houses built for example), the behavioural (in terms of the acceptance and actions of actors) and the symbolic (in terms of the meaning of the issue held by the population at large or segments of it). The mix between these different forms of policy mechanism may vary over time and between countries reflecting the different housing situations and the varying political ideologies. There may be a link between the aims pursued by policy makers and the mechanisms used. For example, the mechanisms designed to achieve behavior modification may be different from those where the aim is to provide more housing. In addition, the forms of policy making may also vary according the aims of policy and the mechanisms used. Recognizing the importance of the behavioural and symbolic aspects of policy is key in understanding the nature of the policy process in housing.

\section{Models of the policy process}

There are many different approaches to understanding the process that governments and other agencies undertake to make housing policy. The traditional distinction is between approaches that focus on a rational analytical process and ones that assume that policy making is an inherently political process that requires agreement between the parties involved. One can also distinguish more structural analyses that see policy being made by an elite group or class. Each of these approaches will now be considered in turn.

Analytical approaches tend to see policy making as a process involving finding information and making decisions based on rational analysis. An example of the approach would be a 'rational decision-making' process that follows a number of steps (see Hogwood and Gunn, 1984). The first would be scanning the environment and gathering information about circumstances and problems; the second would be setting 
objectives in relation to the perceived problems; third is identifying different options for achieving these objectives; fourth is appraising the options and deciding which one achieves the objectives in the most cost-effective way; the fifth step is implementation; and finally the outcome of the policy is evaluated to assess what impact it has had on achieving the objectives set for it. This process is usually seen as an ongoing one in which the evaluation of the outcome feeds in to the first step of the next iteration of environmental appraisal and is used to re-assess and reset objectives and means of achieving them in a continuing cycle. There are many forms of this process, but all share the basic tenets of rational analysis in an ongoing cycle. One criticism of this approach is that it is impossible to achieve in practice as the constraints of time, resources and knowledge mean that it is very difficult- if not impossible- to foresee the costs and benefits of different means of achieving a particular policy and so analysis is usually going to be limited in some way. Simon (1947) adopted the concept of 'satisficing' to describe how policy makers try to be as rational as possible given the constraints they face. Etzioni (1967) put forward a mixed-scanning approach in which he argued that the best approach was for policy makers to continue in an incremental manner for most of the time, but then at certain times (maybe at critical junctures) to take a more comprehensive and rational view to enable more radical change to take place if it was needed. Although both authors voice criticism of the rational approach they remain firmly within the rational category as they share many of its fundamental tenets such as the belief in the importance of 'rational' and value-free analysis.

However, there are more fundamental critiques of the 'rational' approach that place emphasis on the political elements of policy-making. Exemplifying this political approach, Lindblom (1968) argues that the limitations make rational policy making impossible and so policy makers simplify the process by only making incremental changes in a kind of 'trial and error' manner in which change is monitored and, if successful, continued and, if not, discontinued. It is generally accepted that much of government policy making in the real world takes this approach, but the debate focuses on whether this is desirable or whether rational policy making should be more prevalent.

Lindblom's most fundamental critique of the rational approach is that policy is made through a political process that involves bargaining and negotiating between the parties involved. He argues that a good policy is one that is agreed on by the parties involved in it. Agreement means that the policy is more likely to be implemented and to be sustained. Criticism has focused on the assumption that all relevant parties that would be impacted by a particular policy are involved in the policy making process and on the importance of imbalances of power between them in determining the final outcome. Some parties may be powerful, resourceful and well organized and so able to set the terms of the debate and enable adoption of their preferred solution whereas others may be powerless and disorganized. The awareness of this imbalance led to advocacy planning in which the concern was to help powerless people to enter the process and make an impact on policy.

As well as raising the question of power, Lindblom's (1968) focus on the political process raises issues around discourse and agenda setting. He argues that parties may have different views on the problems and the issues involved and there may need to be agreement on what the problem is as well as how to deal with it once defined. Similar 
approaches have been put forward by authors such as Healey (1997) and Fischer and Forrester (1993) with concepts of 'collaborative' or discursive' planning that recognize the importance of different discourses held by different agents in the policy-making process and the importance of the process of communication and negotiation between them.

A third approach to understanding the policy making process is a structural one involving a class-based analysis. For example, Foucault has used the term 'governmentality' to highlight the different strategies and mechanisms that governments use to promote the interests of the dominant class and to sustain a particular discourse and policy direction. This analysis highlights the distributional aspects of policy as well as behavioural aspects such as the 'conditionality' of welfare benefits and the policing and self-policing elements of behavioural change. The emphasis on the behavioural aspects of policy provides an insight that is lacking in the other approaches and can shed light on the ways that policies are structured to pursue changes in the behavior of different agents. The focus on discourse is similar to that of the political approach except that assumptions about the power balance in society differ. Many structural approaches do place emphasis on the balance between agency and structure and assume that policy is not just in one top-down direction. There is a focus on resistance to control mechanisms and on social movements that can impact on the power of dominant discourses and foster alternatives to them.

In summary, there is little agreement about how housing policy should be or is actually made. The three main approaches are the rational approach that places emphasis on analysis using social facts; a political approach in which different groups and organisations negotiate and bargain over the discourse of the issues and problems and their solutions; and a structural approach that places emphasis on control and behavioural change. Whichever process applies may be informed by analysis by policy makers, academics or pressure groups, but in the latter two approaches this is not a rational process as their analyses may have very different discourses embedded in them, and there is not one right policy that can be ascertained through rational analysis. Therefore, each of the different approaches to the policy making process has a different role for policy research and suits different forms of research. For each policy making approach there is a form of research that best fits it, as will be explained in the next section.

\section{Housing Research and Policy}

The precise nature of the policy making process has a profound influence on the kind of housing research that is appropriate to influence policy. Each of the three approaches and the way that research fits them will be explored in this section. The example of research on homelessness is used, though not to show the impact of specific research studies on policy, which is outside the scope of this paper. Rather, the aim is to give an example of the kind of research that could fit the given policy-making approach.

\section{The rational approach}

For a rational process there is an implicit positivist and empirical approach. The search is for social facts that can prove the existence of certain phenomena or allow the judgment of the success of a particular policy. The rational approach would look to 
answer questions about the outcomes of a policy by saying that a good policy achieves the objectives laid down for it. But objectives may not be explicitly stated and not everyone may agree what they are either in general or for specific policies. Also, it is important not to focus exclusively on objectives as many policies have unintended outcomes as well as intended ones and these may be important in terms of their acceptability to politicians and people in general as well as the overall judgment of their worth. Also, many of the most important housing objectives relate to the condition, distribution and affordability of housing and so measuring the success of policies depends on being able to identify and assess their impact on the housing outcomes of individual households. Therefore, evaluation has to focus on outcomes. However, this is not as simple as it sounds. There is a distinction between outputs that are the direct result of policy and the outcomes that are the impacts on the lives of people and on the society in general. For example, the output of a policy to support new house building may be considered to be the number of houses built, but the outcomes are the feelings of security and well-being felt by the people who make homes in those houses, as well as the impact on the well-being of the wider society, for example through greater social cohesion.

The impact of housing policies may differ between individuals and groups. For example, a policy may provide financial support to house builders and increase their profits, but it may not result in more houses being built and so may not help those who are looking to buy a house. Some policies may lead to an increase in the price of existing houses, which helps those already living there, but they may hinder those seeking to buy. Differences in income, wealth, gender, ethnicity and physical and mental ability may result in different outcomes from the same housing policy. Therefore, evaluation should ensure that the variable impact is considered.

In homelessness there has been a lot of research using this approach. Examples are the work by Culhane (2008) and others in looking at the costs and benefits of different ways of dealing with homeless people. A number of research studies showed that the costs of supporting homeless people through forms of transitional accommodation were high and the outcomes were less than those of interventions that prioritized the move into independent housing. This led to the formulation of the 'Housing First' approach that has been adopted in many countries. 'Housing First' appeals to politicians anxious to constrain public expenditure as well as homelessness advocates looking to see a better outcome for homeless people.

\section{The political approach}

The political approach to policy making alerts us also to the existence of different sets of objectives held by different groups in society. Rather than accepting the dominant discourse and the objectives that flow from it, analysis should take into account the different perspectives and values that are implicit in alternative discourses.

So, if it is assumed that the policy process is a pluralistic bargaining between interest groups, empirical researchers can expect their findings to be debated and contested as part of ongoing negotiations. It could be argued that this form of research can improve the outcomes by changing the nature of the bargaining involved by improving the information on which the debate is based. However, this approach still neglects the presence of different discourses and definitions of the problem to be addressed. If 
policy-making is about the reconciliation of different perspectives and discourses, then rational analysis may not help this process.

Research based on a social constructionist perspective that emphasizes the socially constructed and contested nature of reality seems best suited to the political approach. Research that elucidates and analyses different discourses held by different groups would help to inform policy by providing information for the bargaining process rather than providing a 'right' solution that would transcend any debate. Therefore, the focus in the research would be the elucidation of discourses and attitudes and perceptions. Analysis can highlight logical inconsistencies in any discourse and compare discourses and research evidence in terms of socially constructed 'facts'. The research may highlight agreements and differences between discourses and so help in the bargaining process.

The political nature of policy making is recognized by many decision-makers today as evidenced by the large extent of research undertaken by pressure groups and think tanks' that share the same discourse as the decision-maker. Even where a rational analysis is undertaken its findings may be subjected to political analysis through the lens of the decision-makers' discourse. A current example in the UK is the debate over the increase in airport capacity in the south-east of England. A report developed following the rational approach described above was commissioned by government, and it suggested a third runway should be built at Heathrow airport (Airports Commission, 2015). However, the results of this report were further analysed by government ministers who have only committed themselves to the suggested solution after considerable further analysis and debate. Various factors have been taken into account, including the impact on political support in various locations, and attempts have been made to put together a policy package that maximizes political support and minimizes opposition.

In the field of homelessness there has been substantial research that has examined the discourses that have framed policy (see Jacobs, Kemeny and Manzi, 1999). This research is relevant to discussions about the discourses that have shaped the definition of the problem and its causes and appropriate remedies. This kind of research helps groups involved in the policy process in identifying and defining different discourses and uncovering their underlying assumptions. Social constructionist research has also explored the personal circumstances and perceptions of homeless people themselves and allowed their voices to be heard in policy deliberations and in the campaigning activities of voluntary organisations. Research on policy options has examined the symbolic and experiential elements of different forms of provision for homeless people (see Clapham, 2015).

\section{The structural approach}

There are many different structural analyses. The Foucauldian perspective considers issues of discourse and governmentality. Research in this tradition highlights the historical evolution of discourses and their impact in terms of the distribution of costs and benefits and the constraints on behavior through the instruments of policy. Other structural approaches include critical realism and recent literature on 'varieties of residential capitalism' that seeks to show the impact of factors such as financialization 
on the trajectory of different national housing systems (see Schwartz and Seabrooke, 2009; Aalbers, 2016). In these approaches there have been major research emphases on the historical changes in policy over time and their underlying causes (see Lawson 2006). But the approaches also focus on the relationships between agency and structure and can draw attention to the contextual factors that influence behaviour as shown in the example of work on homelessness considered below. The emphasis on discourses and control mechanisms sheds light on the behavioural and symbolic elements of policy. Research of this kind may be of benefit to governments concerned to improve their policies and mechanisms, but it may also be important in changing public perceptions of dominant discourses by providing insight into the mechanisms used and their impact. The research may also be important to social movements and other resistance groups by providing alternative discourses and offering information on the impact of policies.

An example of the critical realist approach in research concerned with homelessness is provided by Fitzpatrick (2005), who elucidated the underlying structural factors that increase the likelihood of homelessness among individuals and the individual trigger factors that lead to an experience of homelessness. This research places emphasis on the contextual factors that frame individual behavior by examining the relationship between agency and structure. An important element of this context is government policy on issues such as welfare benefits that can make it difficult for households to afford the rent and may be a factor in the recent increase in homelessness in the UK.

\section{Summary}

The aim of this section has been to show that there are different views of the policymaking process and that different traditions of housing research fit in different ways with these approaches. It is not suggested here that one model of policy-making is better than another. This may indeed be a conclusion of individual researchers that will shape their work. However, different approaches to policy making may dominate in different countries and at different times and on different topics. The major point is that each of these traditions of housing research can have an impact on policy depending on the nature of the policy-making process. Therefore, there is not necessarily one model of research that is superior to others in its impact on policy. This means that there is no necessary contradiction between researchers pursuing different approaches in trying to inform policy debates; research done from a variety of perspectives may have an impact on policy.

The next stage in the argument is to show that all research on housing policy needs to be theoretically and conceptually informed. This is a further step in undermining the idea of a schism in housing research, and it reinforces Kemeny's call for more theoretically oriented research.

\section{The Necessity of Theoretical Engagement}

This section engages with the argument that policy related research does not have to be conceptually or theoretically informed and argues that policy research and theoretical research are not different and separate. It has been shown in the previous sections that research based on quite different theoretical positions has policy relevance depending on the policy process involved. But does research aimed at changing housing policy 
have to be theoretically informed? As a prelude to the main argument it is necessary to define what we mean by both theory and research.

There are different views on what constitutes theory. Abend (2008) identifies seven different meanings of the term 'theory' in sociology. This is evidence that the meaning of theory will vary according to different paradigms. For example, some may look for a theory to include a statement of causation, but others would not. Here I take a very general definition of theory as being;

'collections of concepts about the real world that facilitate explaining, predicting, or intervening'.

Theories explain why and how things occur. They help to predict what is going to happen in the future given the way things are at present and have been in the past, and they help people and governments to choose actions to achieve objectives to further desired future states. Therefore, theory enables description and understanding of social events and trends and gives insight into events in the future. In particular, this provides the tools to be able to intervene in the real world and to predict the outcomes of the intervention. In a similar way Ruonavaara (this issue) views social theory as a discourse that consists of a set of linked (a) concepts and (b) propositions to be used for hypothetical (i) re-description, (ii) explanation and (iii) interpretation of all or some subset of social entities and processes. So the concepts and propositions provide (i) redescriptions of social entities and processes relevant to the conceptual scheme designed (re-description), (ii) hypotheses of why and how the entities/processes are as they are (explanation), as well as (iii) ideas of their meaning in the cultural and social context where they exist (interpretation). It is unclear in this formulation whether all three elements need to be present in order for something to be considered a theory. Here I assume that anything that has a linked set of concepts and propositions constitutes theory even if it is just used for the re-description identified by Ruonavaara, because such a linkage could be used for explanation and interpretation even if this is not done in a particular study. In a field such as housing policy it seems difficult to understand how researchers would be able to do these things that are fundamental to housing policy without being able to generalize through the use and production of theory.

Although the concept of theory has been defined, it is also necessary to define what is meant here by research. It is possible to get into a tautological situation by defining research in terms of the concept of theory outlined above. In other words, research can be considered to involve description, explanation and interpretation. In this formulation, by definition, all research involves theory and this is the position adopted here. It is possible to draw a distinction between description and the other two functions of research, explanation and interpretation, but the same argument could be used with regard to theory as well.

However, the argument here does not rely on this tautology of definition but considers in more depth whether any research can be theoretically or conceptually free. Such a claim can really only be even superficially sustained in the case of empiricist and positivist research that searches for social facts that it takes to be self-evident and uncontestable. However, although such a study may not explicitly engage with theory, it does of course rest on an implicit position that should be (although often isn't) stated 
and argued. Essentially all social research is based on a theoretical foundation and so all social research is theoretically informed, even if it does not recognize this. If this is the position, then it is axiomatic that the theoretical framework used should be explicitly stated and open to inspection and analysis.

That this is not the case in much research aimed at influencing housing policy, particularly that funded by governments, needs some reflection. A feature of many governments is the distinction between the political process peopled by politicians and the administrative process peopled by civil servants (see Hogwood and Gunn, 1984). In practice, of course, these roles are often blurred and difficult to keep separate. Nonetheless, the prevailing discourse is that civil servants are neutral aides to policy making who accept the objectives of the politicians, whoever they are. This view reflects that of the rational policy making approach where it is assumed that objectives can be set by the political process whereas the means to achieve them are value free and can be ascertained by civil servants through neutral analysis. This position is, of course, unsustainable in practice because the means of achieving the policy objectives are rarely value free and may be as important and contentious as the objectives themselves (just think again of the current debate about the siting of extra airport capacity in the south-east of England). The different means to achieve policy objectives may have different distributional impacts on social groups and may have profound symbolic importance.

Despite the problems of the policy/administration split, it is still the predominant discourse in many countries and it frames research on policy. So politicians and political advisers are allowed to commission and read the research of pressure groups and think tanks that share their overall ideologies and discourses, but civil servants are supposed to read and commission 'neutral' and value free research to inform the policymaking process. The research approach that best fits this latter form is empirical and positivist research that views itself as searching for universal truths based on social facts. Critical realism or social constructionism would be viewed as too value laden for the neutral approach desired. Of course this neutrality is a sham borne of the inadequacies of the positivist paradigm and the usual reluctance to make the framework explicit.

Therefore, it is argued that any kind of research, including empiricist and positivist studies, has a theoretical framework that should be made explicit rather than remain implicit, as in often the case. Although the positivist paradigm is not common in many social science disciplines, it still holds sway in much economic research and even behavioural economic analysis includes only positivist psychological concepts, and its proponents ignore insights from other social science disciplines such as economics or geography (as well as many areas of psychology) that have adopted other paradigms. There is not the space here to rehearse the well-known criticisms of positivism, and the argument here is not that positivism is an inappropriate research paradigm. Rather, the argument is that the theoretical and conceptual basis of any paradigm should be explicit. Therefore, research in any paradigm engages with the social theory that frames the paradigm even if it is not explicit. Research can either adopt and use a theoretical framework without changing it or it can actively engage with theories and concepts and attempt to amend and supplement existing ones. It may be that policy related research 
is often the former rather than the latter, but this does mean that it engages with theory even then.

Therefore, the key argument here is that the appropriate distinction is between research that makes theory by breaking new ground in theoretical and conceptual development and research that only seeks to apply theory without developing it. Both can legitimately claim to be engaged with social theory. However, there are different levels of theory. One can say that paradigms are the most general element of theory, but within paradigms there may be theories that have general application, and others that may only be used in specific contexts such as housing. The argument in the previous paragraphs relates most clearly to the paradigmatic and general theories that underpin the approach that researchers take, but almost all research uses concepts to pattern the findings of empirical research. Even research that could be described as descriptive, uses concepts to aid understanding of the phenomena studied and the relationships between them, which would be included in our definition of theory.

Kemeny (1992) argued for the introduction of social theory to housing but did not specify the level at which this should take place. It is more apparent that general theories can be applied as discussed above with regard to paradigms of research. However, it is at the more specific level that the application of theory becomes more problematic and where the charge of neglecting theory can be sustained. This leads us to the question of whether lower-level theories can be applied to housing or whether there needs to be a set of theory that is unique to housing. To explore this, the nature of housing first needs to be considered.

\section{The Nature of Housing}

Housing is a complex and unique commodity that has many different elements and so is difficult to encapsulate easily. Unlike many commodities bought in a shop, each house has a unique mix of attributes, similar to and yet never the same as in other houses. For example, each house has a unique location and so a unique set of location-dependent affordances. But there are many other attributes of a house. Houses can also be homes and this means that many different aspects of identity and meaning get attached to the more functional aspects of a house, such as the ability to access labour markets and public and private facilities such as shops, leisure amenities, health care and schools. A house is also an important positional good in many societies in that it signals status as well as access to resources. Therefore, housing can be important in issues of social cohesion.

A house is the major location for family life and the place where family members spend the majority of their time. It is a basic foundation for life and there is extensive evidence of the importance of the home environment in influencing the educational achievement and health of family members (for a review see Clapham, 2005). In addition, a house is a major family expenditure whether it is bought or rented and so has a major influence on living standards. Houses can also increase in value and they represent a high proportion of household wealth in many countries. Therefore, housing may be an important influence on the distribution of both income and wealth in a society as housing is both an investment and a consumption good. Governments that have an 
interest in intervention in the distribution of income and wealth are likely to look towards housing as an important mechanism through which to achieve societal goals.

\section{Housing as a market commodity}

The unique qualities of housing mean that it is unlike most consumer goods. Because it is expensive, housing is long lasting and so most households only transact in the market a small number of times, especially if they are buyers. The fact that the institutional structure of tenures determines the rights and obligations of residents means that the market is divided into rental and ownership categories that are separate in their everyday functioning, though strongly linked because prices in one will influence the prices in the other and these relative prices will influence the size of the respective categories.

The difficulties involved in a housing market are summed up in the two contributions considered below. First, Mowen (1990 p.676) identifies five factors that make up the traditional neo-classical approach to consumer behaviour, which are as follows:

- Rational behaviour

- Well-defined preferences and a knowledge of the satisfaction that will be gained from consumption of the product

- Perfect information about the product and market functioning

- Decisions subject to budget constraints

- Insatiable desires (i.e., more of a product will always increase satisfaction)

The important point here is that none of these factors holds true for housing. For example, it is clear that much household behaviour in purchasing housing is emotional as well as rational. People make calculations about their housing choices, but also have emotional feelings about particular houses that may or may not feel like home. Preferences may not be well defined because there are so many trade-offs involved between the many different attributes of a house and it is unlikely to get a perfect fit. In addition, it may be difficult to foresee whether one is going to be happy in a particular house because many of the affordances may only become apparent as lifestyles evolve in a different physical location. Also it is unlikely that households will have a perfect view of the future movement of house prices that can of course rise and fall over time and vary greatly between locations. It may be very difficult to tell whether a particular neighbourhood will become gentrified with the resultant price increases or deteriorate with price reductions. It is also possible that more housing may not increase consumer satisfaction because of its multi-faceted nature. What constitutes 'more' may vary between individuals. Having more in terms of physical space may bring problems of maintenance or cleaning, and people may feel isolated or ill at ease in a large space.

The second contribution is by Maclennan (1982) who identifies seven distinctive features of the housing market (1982, pp.60-62) which render the use of standard consumer theory problematic:

- Individuals transact in the housing market infrequently, which means that consumers possess imperfect information regarding the state of the market.

- In the period between an individual's transactions the market will have changed and evolved; therefore, any information that the individual possesses may be obsolete. 
- Because it is costly to recontract in the housing market, imperfect information is likely to lead the consumer to engage in a costly search process.

- The fact that housing is a complex commodity exacerbates consumer problems in evaluating possible purchases.

- Evaluation is made more difficult by the spatially dispersed nature of vacancies.

- The process of house purchase entails engagement in some form of bidding.

- Because of the fixity of the second-hand housing stock, the relatively slow rate of turnover and relatively sluggish new supply, there is likely to be considerable disequilibrium in particular submarkets as a result of changes in demand.

These deviations from the neo-classical assumptions mean that some features of this model may not be present in a housing market. For example, supply may be inelastic in that it is slow to respond to changes in demand, a feature that has been shown in many different national housing markets. This means that markets may not 'clear' in the neoclassical sense with markets able to stay in disequilibrium for long periods of time. Disequilibrium may mean long term problems of housing shortage or unaffordability that the market itself cannot correct in the way that neo-classical theory would predict, thus opening the door for state intervention.

The unique features of housing mean, at the very least, that the application of disciplinary theory (whether from any of the mainstream disciplines) is likely to be problematic. I have illustrated this with respect to neo-classical economics which is unlikely to reflect the unique qualities of housing and a similar argument might be applied with sociological or psychological theories. This reinforces the search for a 'theory of housing' that encapsulates the essence of its unique features. There have been a number of attempts to forge a theory of housing, but with little success. Kemeny himself tried to build a theory of housing around the concept of 'residence' but this has not been widely adopted. King (2009) has also done so, but again with little impact. The search continues for a 'theory of housing'.

But the search for a single theory of housing may be misplaced. The complexity of housing has meant that it has been examined through the lens of different disciplines, each of which has offered important insights. Bringing these together into a coherent single theory is extremely desirable, but it is probably not possible to achieve at present. The different disciplines have very different paradigms and concepts that are often incompatible. There has been little truly inter-disciplinary or trans-disciplinary research in the housing field (Clapham, 2009) and this is probably necessary if an overall theory is to be devised. Therefore, at the present state of the art it seems that the most that can be expected is for the derivation of a number of trans-disciplinary concepts that could eventually be built up into a universal theory of housing.

\section{Conclusion}

Jim Kemeny did the field a major service by arguing for more theoretically oriented housing research. However, the argument of this paper is that the dichotomy that underpins his critique of housing research is flawed. The paper has shown that all housing research is theoretically engaged. Further, I have argued that policy research needs to have an explicit theoretical foundation if it is able to explain phenomena and enable us to predict future issues and to guide the production of policy and to predict its 
impact. All housing research engages with theory, although often the theoretical basis and the concepts used are not made explicit. The argument here is that clarity and explicitness of paradigms and concepts is a basic requirement of research. Then the important distinction is between research that uses existing theory and that which amends or extends theory.

The paper has also shown that the dichotomy between policy research and theoretically informed research is a false one. I have shown that the view that the policy process needs a certain kind of empirical and 'theory free' research is mistaken. I have argued that there is not one ideal type of policy research, but rather that there are different kinds of research that suit different forms of policy making approaches. What is needed in the future is an analysis of different policy-making processes in housing and their relationship to different theoretical approaches. This could be achieved through the use of case studies of links between research and policy-making in order to understand the way that they interact in different situations. Despite the large amount of research on housing issues, there has been a relative neglect of studies of the housing policy-making process. In the 1980s, studies by Dunleavy (1981) and Swenarton (1981) showed the way that specific policies had been made and the role of research and information in this process. There is a need for similar kinds of studies in different contexts now.

However, the use of theory in housing research is problematic as the unique nature of housing means that the application of general theories drawn from other fields is not always useful. Nevertheless, there is scope to design a theory of housing that may be drawn partly from existing concepts that fit the housing context, as well as through the design of concepts that emerge from the specific nature of housing itself. Although the production of a specific, trans-disciplinary theory of housing is not practicable at the current state of knowledge, it should be a major priority to derive and test out the specific concepts that are needed to build the theory.

\section{References}

Aalbers M. (2016) The Financialisation of Housing: A political economy approach. London and New York: Routledge

Abend, G. (2008) 'The meaning of "theory"' Sociological Theory 26(2) 173-199

Airports Commission (2015) Final Report ISBN: 978-1-84864-158-7

Clapham D. (2009) 'A theory of housing: problems and potential' Housing, Theory and Society 26.1 1-9

Clapham D (2015) Accommodating Difference: evaluating supported housing for vulnerable people. Bristol: Policy Press

Culhane D. (2008) 'The costs of homelessness: a perspective from the United States' European Journal of Homelessness 97-114

Doling J. (1997) Comparative Housing Policy: Government and housing in advanced industrialized countries. Basingstoke: Macmillan 
Dunleavy P. (1981) The Politics of Mass Housing in Britain1945-75. Oxford: Clarendon Press

Etzioni A. (1967) 'Mixed scanning: a "third" approach to decision-making' Public Administration Review 27, 385-92

Fischer F. and Forester J. (1993) The Argumentative Turn in Policy Analysis and Planning. Duke University Press: Durham and London

Fitzpatrick S. (2005) ‘Explaining homelessness: a critical realist perspective’ Housing, Theory and Society 22(1) 1-17

Foucault M. (1979) ‘Governmentality’ Ideology and Consciousness 6, 5-21

Healey, P. (1997) Collaborative Planning: Shaping places in fragmented societies. Vancouver: UBC Press

Hogwood B. and Gunn L. (1984) Policy Analysis of the Real World. Oxford: Oxford University Press

Jacobs K, Manzi A and Kemeny J. (1999) 'The struggle to define homelessness: a constructivist approach' in Hutson S. and Clapham D. (eds) Homelessness: Public Policies and Private Troubles. London: Cassell

Kemeny J. (1992) Housing and Social Theory. London and New York: Routledge

King P. (2009) 'Using theory or making theory: can there be theories of housing?' Housing, Theory and Society 26.1 41-52

Lawson, J. (2006) Critical Realism and Housing Studies. London: Routledge

Lindblom C. (1968) The Policy Making Process. New Jersey: Prentice Hall

Lukes, S. (1974) Power: A radical view. London: Macmillan

Maclennan D. (1982) Housing Economics: an applied approach. Harlow: Longman

Mowen J. C. (1990) 2nd edition Consumer Behavior New York: Macmillan

Ruonavaara H. (2016) Upcoming this issue

Schwartz H and Seabrooke L. (eds) (2009) The Politics of Housing Booms and Busts. London: Palgrave Macmillan

Simon H. (1947) Administrative Behaviour. London: Macmillan

Swenarton M. (1981) Homes Fit For Heroes. London: Heinemann 
